\title{
Predictors of smoking among male college students in Saudi Arabia
}

\author{
Y.S. Almogbel, ${ }^{1}$ S.M. Abughosh, ${ }^{1}$ F.S. Almogbel, ${ }^{2}$ I.A. Alhaidar ${ }^{3}$ and S.S. Sansgiry'
}

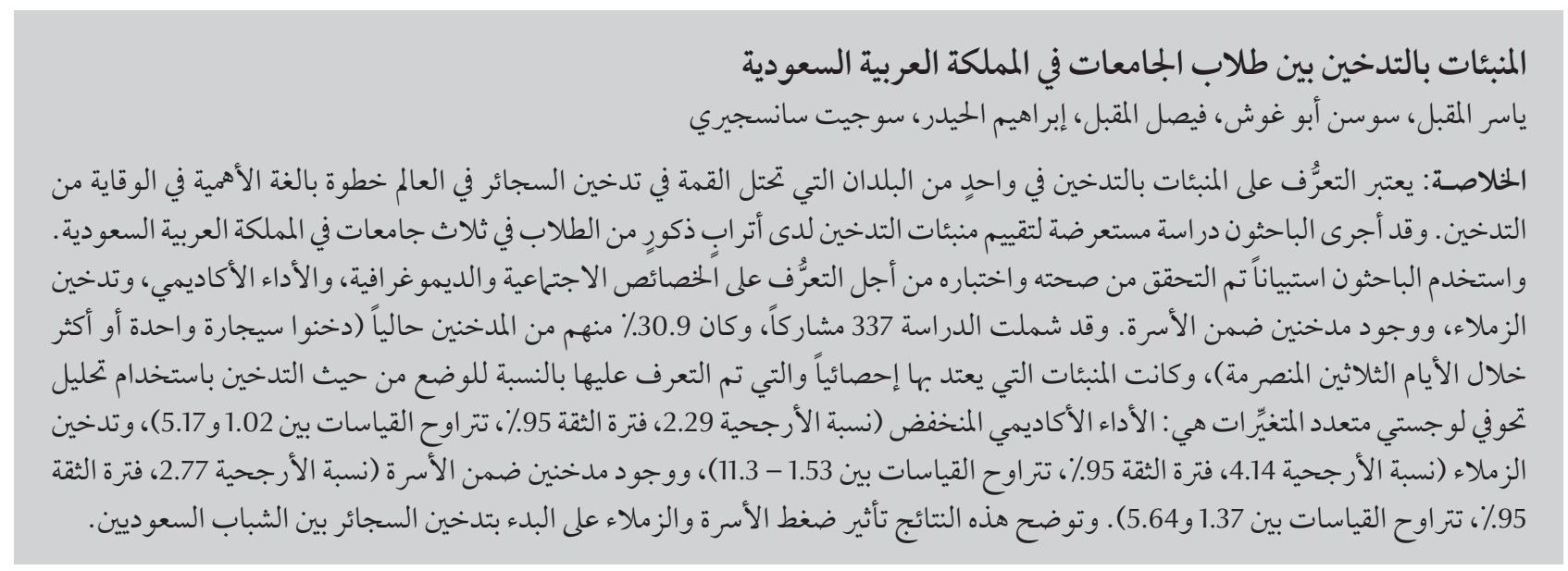

ABSTRACT Identifying the predictors of smoking in one of the top cigarette-consuming countries in the world is a vital step in smoking prevention. A cross-sectional study assessed the predictors of smoking in a cohort of male students in 3 universities in Saudi Arabia. A pre-tested, validated questionnaire was used to determine sociodemographic characteristics, academic performance, peers' smoking, and presence of a smoker within the family. Of the 337 participants, 30.9\% were current smokers (smoked 1 or more cigarettes within the last 30 days). Lower academic performance $(\mathrm{OR}=2.29,95 \% \mathrm{Cl}: 1.02-5.17)$, peer smoking $(\mathrm{OR}=4.14,95 \% \mathrm{Cl}: 1.53-11.3)$ and presence of other smokers in the family $(\mathrm{OR}=2.77,95 \% \mathrm{Cl}: 1.37-5.64)$ were the significant predictors of smoking status identified using multiple logistic regression analysis. These findings highlight the influence of family and peer pressure in initiating cigarette use among the youth of Saudi Arabia.

\section{Facteurs prédictifs de tabagisme chez des étudiants de sexe masculin en Arabie saoudite}

RÉSUMÉ Identifier les facteurs prédictifs de tabagisme dans I'un des premiers pays consommateurs de cigarettes au monde est une étape essentielle dans la prévention du tabagisme. Une étude transversale a évalué les facteurs prédictifs du tabagisme dans une cohorte d'étudiants de sexe masculin dans trois universités en Arabie saoudite. Un questionnaire validé et prétesté a été utilisé pour recueillir des données sur les caractéristiques sociodémographiques des répondants, leurs résultats universitaires, la présence de fumeurs parmi leurs pairs et dans leur famille. Sur 337 participants, 30,9 \% étaient des fumeurs actifs, c'est-à-dire qu'ils avaient fumé au moins une cigarette au cours des 30 derniers jours. Des résultats universitaires plus faibles (O.R. $=2,29$; IC à $95 \%: 1,02-5,17)$, la présence de fumeurs parmi leurs pairs (O.R. = 4,14; IC à $95 \%: 1,53-11,3)$ et dans leur famille (O.R. = 2,77; IC à $95 \%: 1,37-5,64)$ étaient les facteurs prédictifs de tabagisme significatifs identifiés à l'analyse de régression logistique multiple. Ces résultats soulignent l'influence exercée par les membres de la famille et la pression placée par les pairs sur les jeunes d'Arabie saoudite pour qu'ils se mettent à fumer.

${ }^{7}$ Department of Clinical Sciences and Administration, College of Pharmacy, University of Houston, Houston, Texas, United States of America (Correspondence to S.S. Sansgiry: ssansgiry@uh.edu).

${ }^{2}$ Department of Community and Family Medicine, College of Medicine, King Saud University, Riyadh, Saudi Arabia.

${ }^{3}$ Department of Pharmaceutical Sciences, College of Clinical Pharmacy, King Faisal University, Al-Ahsa, Saudi Arabia.

Received: 04/09/12; accepted: 04/11/12 


\section{Introduction}

Smoking is the leading preventable cause of death, responsible for 5.6 million deaths around the world [1-3]. Saudi Arabia is one of the top 10 cigarette-importing countries in the world [3]. The estimated economic, social and health costs associated with all tobacco use in the country was estimated to be $\$ 1.3$ billion in 2010 , with males contributing the most to this estimate [4]. The prevalence of smoking in Saudi Arabia has been reported to be as high as $52.3 \%$, and among school and university students it has reached an alarming rate of $30 \%$ and $50 \%$ respectively [5]. Furthermore, comparison of Global Youth Tobacco Surveys of 13-15-year-olds found a $30 \%$ increase in smoking prevalence in Saudi Arabian males between 2001 to 2007 [6]. The majority of smokers in Saudi Arabia start smoking before the age of 15 years [5]. The price of cigarettes makes them affordable to most children, and there is no strict application of the minimum legal age for purchasing cigarettes [7]. The reported prevalence among men $(13 \%-38 \%)$ is much higher than that among women $(1 \%-16 \%)$ [8], presumably due to the local culture and traditions in Saudi Arabia whereby smoking by females is considered shameful [9].

Addressing factors associated with smoking is a crucial strategy for reducing the number of smokers and improving the health of a nation. A considerable amount of literature has been published on the predictors of smoking, but not specifically within the Saudi Arabia population. Variables such as age, income, academic performance, peer pressure and family members smoking have been shown to be significant predictors of smoking around the world [10-15]. In particular, smoking by young adults was a strong predictor of smoking behaviour in adulthood [11]. A study of 1200 young American adults reported that initiation of cigarette smoking at an early age was associated with higher cigarette consumption, greater nicotine dependence and longer duration of smoking [16].

Cigarette smoking is a major health concern in the male population of Saudi Arabia and the government needs to consider addressing it using behavioural and/or educational interventions. Due to the lack of adequate research in Saudi Arabia on the predictors of smoking behaviour, and considering the cultural differences compared with other nations as well as the high prevalence of smoking in young males, our study sought to identify the predictors of smoking in a cohort of young male Saudi Arabian university students. The goal was to inform strategies that would improve resource allocation to antismoking interventions.

\section{Methods}

\section{Study design and data source}

An observational, cross-sectional study was made to predict smoking among a sample of Saudi Arabian male college students. Data were collected from December 2011 to January 2012 using a pretested, validated, self-administered survey [17]. The survey was distributed in 3 government universities in Saudi Arabia. Two of the selected universities provide general higher education (unspecialized) opportunities. The third institute is a technical college that focuses on computer, engineering and industrial sciences. One of the universities is located in the east of Saudi Arabia (Al Hassa). The second university and the technical college are in the $\mathrm{Al}$ Qassim region, which is located in the central part of Saudi Arabia. The total number of students within the 3 institutes was about 70000 .

Convenience sampling strategy with a goal of at least 400 participants was considered in this study. Within the universities, 4 health and 1 computer school agreed to assist in data collection.
The teaching faculty at each institute assisted in distributing the surveys. Surveys were administered to students during the last 15-20 minutes of their lecture. Students were requested by teachers to participate by anonymously filling out a survey about their smoking behaviour and to drop the completed survey in a box that was available in each lecture room. All boxes were collected after the lectures ended. Participation in the study was voluntary, and an informed consent letter was provided before proceeding with the data collection. The survey was approved by the institutional review board at the University of Houston.

\section{Survey design}

The questionnaire was developed in English and translated into Arabic language using a translation and backtranslation method [18]. The translated survey was validated with the help of 3 bilingual experts and was pretested for reliability using the test-retest reliability method for 10 subjects before commencing the data collection.

The variables considered in this study were part of a larger survey that consisted of 56 questions divided into 7 sections in a 4-page-long survey. In this study, the variables considered were smoking status, age, age first initiated smoking, income, marital status, academic performance, peer smokers and presence of smokers within the family, such as mother, father, brother or any other family member (non-first-degree relative).

Smoking status was the main outcome variable evaluated, and a participant was considered a current smoker if he had smoked 1 cigarette or more within the last 30 days. Age was divided in 4 groups, from 18-20 years to $>26$ years. Participants were also asked to report age of initiation of smoking. Income was divided into 2 categories according to maximum financial aid for Saudi students: > 12000 Saudi riyals/year (US\$ 3200/year) 
and $\leq 12000$ Saudi riyals/year (US\$ $3200 /$ year). The marital status variable was classified as single or married. Students' academic performance was measured by asking the participant what grade they received in school, with 4 choices: A, B, C or D. For peer smokers, respondents were asked if any of their friends were smokers (yes or no). The presence of a smoker within the family was categorized using 4 variables: mother, father, brother or any other smoker at home (nonfirst-degree relative). Participants were asked if any of their family members were smokers or former smokers (yes or no). These variables were selected based on previous studies and through pilot testing [10-15].

\section{Statistical analysis}

Descriptive statistics and bivariate analysis was used to identify the predictors of smoking. Any variable with a probability of 0.2 or less in the bivariate analysis was retained in the final multiple logistic regression. A multiple logistic regression model was performed to determine the predictors of smoking. Data were coded and entered using Microsoft Excel 2010, and data was analysed using $S A S$, version 9.3 .

\section{Results}

A total of 467 out of 920 surveys were received from students at the 3 universities, a net response rate of $50.8 \%$. Due to data missing for the main outcome variable, 130 surveys were excluded providing a net response rate of $36.6 \%$. The mean age was 22.2 (SD 2.2) years. The majority $(66.5 \%)$ of participants were between 21 and 23 years old and single marital status (96.3\%) (Table 1). Nearly two-thirds of participants (77.4\%) were receiving $\leq$ US\$3200/year. Most respondents (79.5\%) had scored A or B throughout their academic life. About $78.2 \%$ of participants reported that they had at least 1 smoker friend and 33.4\% had at least 1 smoker brother. About $34 \%$ of participants indicated that they had 1 or more other smoker members of their family at home (non-first-degree relative).

Almost one-third of participants (104, 30.9\%) were current smokers. The average reported age for initiating the smoking habit was 15.0 (SD 4.7) years, with a median of 16 and a range of 8-30 years.

The results of the bivariate analysis of smoking status are summarized in Table 1. Significantly more smokers $(29.8 \%)$ had a reported income > US\$3200/year than did non-smokers $(19.3 \%)(P=0.033)$. Smokers had significantly lower educational grades that non-smokers, e.g. $29.7 \%$ had achieved grade A versus $44.8 \%$ of non-smokers $(P=0.004)$. Significantly more smokers than non-smokers reported having at least 1 friend who smoked (92.9\% versus $72.3 \%)(P<0.001)$, having at least 1 smoker brother (43.7\% versus 29.3\%) $(P=0.017)$ and having 1 or more smoker non-first-degree relatives at home (48.2\% versus $28.4 \%)(P=$ $0.001)$.

Table 2 presents the results of the multiple logistic regression of smoking status with all variables that had a significant level of 0.2 or less in the bivariate analysis. The risk of smoking increased about 2-fold (OR $=2.29,95 \%$ CI: 1.02 5.17) with low academic performance (grades C to D). The risk of being a smoker was higher for respondents with friends who smoked (OR $=4.14,95 \%$ CI: 1.53-11.3) and with other smokers in the family (non-first-degree relatives) $(\mathrm{OR}=2.77,95 \% \mathrm{CI}: 1.35-5.64)$.

\section{Discussion}

In our cohort of male university students, the percentage of current smokers, i.e. individuals who smoked at least 1 cigarette during the last month, was $30.9 \%$. This was consistent with 2 other studies that were conducted in similar geographic areas to our study. One carried out in 2003 on 2203 secondary-school male students in $\mathrm{Al}$ Qassim, Saudi Arabia found that 29.8\% of respondents were smokers [19]. The second study in 2006 on 1652 secondary male students in $\mathrm{Al} \mathrm{Hassa,} \mathrm{Saudi}$ Arabia found that $30.3 \%$ were current smokers [20]. In the current study, the influence of peers and families on smoking behaviour was apparent. Peer smokers such as friends and the presence of other smokers (other than father, mother or brother) at home were significant predictors of smoking status for male college students in Saudi Arabia. Academic performance was associated with smoking status, as low grades increased the risk of smoking.

Smoking in American adolescence and young adulthood has been reported as a predictor of adult smoking [11]. In the current study, age was not associated with smoking status because most smokers in Saudi Arabia begin smoking at an early age (mostly below 15 years) [21-23] and our sample had a narrow focused cohort of only university students. The average age of this sample was 22 years, as the entire sample was recruited from the undergraduate college student population. Thus, the age effect was not, or might not be, captured in this study.

Income in our study was associated with an increase in risk of smoking in the bivariate analysis but was insignificant after controlling for potential confounders in the multiple logistic regression model. This result differs from a survey by Khader et al. in 2005 on 712 university students in Jordan [10]. They found that income increased the risk of smoking among students.

Academic performance was a significant predictor of smoking in our study. Students with lower grades (C to D) were found to have a 2.3 times greater likelihood of being smokers compared with those who had higher (A) grades. The academic performance variable was used in 2 previously reported smoking 


\begin{tabular}{|c|c|c|c|c|c|c|c|}
\hline \multirow[t]{2}{*}{ Characteristic } & \multicolumn{2}{|c|}{$\begin{array}{c}\text { Total } \\
(n=337)^{\mathrm{a}}\end{array}$} & \multicolumn{2}{|c|}{$\begin{array}{l}\text { Non-smokers } \\
\quad(n=233)\end{array}$} & \multicolumn{2}{|c|}{$\begin{array}{l}\text { Smokers } \\
(n=104)\end{array}$} & \multirow[t]{2}{*}{$P$-value } \\
\hline & No. & $\%$ & No. & $\%$ & No. & $\%$ & \\
\hline \multicolumn{8}{|l|}{ Age group (years) } \\
\hline $18-20$ & 50 & 15.7 & 39 & 17.3 & 11 & 11.7 & 0.132 \\
\hline $21-23$ & 212 & 66.4 & 150 & 66.7 & 62 & 66.0 & \\
\hline $24-26$ & 42 & 13.2 & 24 & 10.7 & 18 & 19.1 & \\
\hline$>26$ & 15 & 4.7 & 12 & 5.3 & 3 & 3.2 & \\
\hline \multicolumn{8}{|l|}{ Marital status } \\
\hline Married & 12 & 3.7 & 7 & 3.1 & 5 & 5.0 & 0.391 \\
\hline Unmarried & 316 & 96.3 & 221 & 96.9 & 95 & 95.0 & \\
\hline \multicolumn{8}{|c|}{ Income (US\$/year) } \\
\hline$>3200$ & 76 & 22.6 & 45 & 19.3 & 31 & 29.8 & 0.033 \\
\hline$\leq 3200$ & 261 & 77.4 & 188 & 80.7 & 73 & 70.2 & \\
\hline \multicolumn{8}{|c|}{ Academic performance } \\
\hline Grade A & 133 & 40.2 & 103 & 44.8 & 30 & 29.7 & 0.004 \\
\hline Grade B & 130 & 39.3 & 90 & 39.1 & 40 & 39.6 & \\
\hline Grades C to D & 68 & 20.5 & 37 & 16.1 & 31 & 30.7 & \\
\hline \multicolumn{8}{|c|}{ Having a smoker friend } \\
\hline Yes & 233 & 78.2 & 154 & 72.3 & 79 & 92.9 & $<0.001$ \\
\hline No & 65 & 21.8 & 59 & 27.7 & 6 & 7.1 & \\
\hline \multicolumn{8}{|c|}{$\begin{array}{l}\text { Current or former } \\
\text { smoker in the family } \\
\text { All (as a family) }\end{array}$} \\
\hline Yes & 116 & 38.0 & 90 & 41.5 & 26 & 29.5 & 0.052 \\
\hline No & 189 & 62.0 & 127 & 58.5 & 62 & 70.5 & \\
\hline \multicolumn{8}{|l|}{ Mother } \\
\hline Yes & 60 & 19.9. & 43 & 20.1 & 17 & 19.3 & 0.890 \\
\hline No & 242 & 80.1 & 171 & 79.9 & 71 & 80.7 & \\
\hline \multicolumn{8}{|l|}{ Father } \\
\hline Yes & 119 & 39.4 & 80 & 37.0 & 39 & 45.4 & 0.182 \\
\hline No & 183 & 60.6 & 136 & 63.0 & 47 & 54.7 & \\
\hline \multicolumn{8}{|l|}{ Brother } \\
\hline Yes & 101 & 33.4 & 63 & 29.3 & 38 & 43.7 & 0.017 \\
\hline No & 201 & 66.6 & 152 & 70.7 & 49 & 56.3 & \\
\hline \multicolumn{8}{|c|}{$\begin{array}{l}\text { Any other smokers in } \\
\text { the family }\end{array}$} \\
\hline Yes & 99 & 34.0 & 59 & 28.4 & 40 & 48.2 & 0.001 \\
\hline No & 192 & 66.0 & 149 & 71.6 & 43 & 51.8 & \\
\hline
\end{tabular}

${ }^{a}$ The numbers may not total 337 for some variables due to missing values.

predictor studies [12,14]. Both of these studies found a strong association between low academic performance and smoking, which was consistent with our study findings. The first study was conducted on American students in 1992, and found that lower grades increased the likelihood of smoking status by 2.6-fold [10]. The second study was done in 2005 on Jordanian students and reported that having grade $\mathrm{C}$ was associated with a 4 -fold risk of smoking compared with having grade $\mathrm{A}[12]$.
Consistent with the reported literature, our study found that having at least 1 smoker friend increased the risk of being a smoker 4-fold. A study in 2006 on middle- and high-school students in Cyprus reported that the strongest predictor of smoking during 


\begin{tabular}{|c|c|c|}
\hline Variable & OR $(95 \% \mathrm{CI})$ & $P$-value \\
\hline \multicolumn{3}{|l|}{ Age group (years) } \\
\hline $18-21$ & 1 & \\
\hline $21-23$ & $1.40(0.59-3.35)$ & 0.448 \\
\hline $24-26$ & $1.43(0.47-4.29)$ & 0.527 \\
\hline$>26$ & $1.11(0.23-5.29)$ & 0.897 \\
\hline \multicolumn{3}{|l|}{ Income(US\$/year) } \\
\hline$>3200$ & $1.57(0.81-3.07)$ & 0.186 \\
\hline$\leq 3200$ & 1 & \\
\hline \multicolumn{3}{|c|}{ Academic performance } \\
\hline Grade A & 1 & \\
\hline Grade B & $1.40(0.71-2.76)$ & 0.328 \\
\hline Grades C to D & $2.29(1.02-5.17)$ & 0.045 \\
\hline \multicolumn{3}{|c|}{ Having a smoker friend } \\
\hline Yes & $4.14(1.53-11.3)$ & 0.005 \\
\hline No & 1 & \\
\hline \multicolumn{3}{|c|}{ Current or former smoker mother } \\
\hline Yes & $0.56(0.22-1.39)$ & 0.209 \\
\hline No & 1 & \\
\hline \multicolumn{3}{|c|}{ Current or former smoker father } \\
\hline Yes & $1.58(0.80-3.13)$ & 0.185 \\
\hline No & 1 & \\
\hline \multicolumn{3}{|c|}{ Current or former smoker brother } \\
\hline Yes & $0.91(0.44-1.87)$ & 0.8 \\
\hline No & 1 & \\
\hline \multicolumn{3}{|c|}{$\begin{array}{l}\text { Any other current or former smoker in } \\
\text { the family }\end{array}$} \\
\hline Yes & $2.77(1.37-5.64)$ & 0.005 \\
\hline No & 1 & \\
\hline
\end{tabular}

$O R=$ odds ratio $; C l=$ confidence interval.

both early and late adolescence was peers' smoking status, as it increased the smoking risk by 20 -fold [14]. Additionally, a study conducted in 2010 on male Saudi Arabian school students aged 16-18 years reported that having peer smokers increased the risk of smoking by 3.5 -fold [24].

A longitudinal study conducted between 1991 and 1994 on 3rd to 8th grade students in the United States reported that having a family member who smoked at home was a significant predictor of smoking at an early age [15]. In our study having 2 smokers in the family, i.e. brother and any other related to in their social context, rather than their father.

A number of limitations need to be considered before applying the findings of this study. Crosssectional study designs can identify the association between a predicted variable and the predictors, but cannot establish causality. The generalizability of these findings is limited to similar populations of college students in Saudi Arabia. Finally, this study was done using a convenience sample. Therefore, non-participants were not characterized and the influence of non-participation due to possible reporting of smoking behaviour was not captured.

The results suggest that an educational and consultation programme for families could be effective in reducing the number of smokers. Furthermore, educating students on the harm of smoking and the impact of peers could aid in the prevention of smoking. Starting such educational campaigns at an early age may influence students to not initiate smoking. Educational advertisements that highlight the role of family and the role that friends play in the process can provide added benefit in reducing smoking behaviour in Saudi Arabia.

\section{Conclusions}

This study identified predictors of smoking in male college students in Saudi Arabia. We found that lower academic performance, peer smoking and the presence of other smokers in the family were significant predictors of smoking status. Despite application of the WHO Monitor Protect Offer Warn Enforce Raise (MPOWER) framework recommendations in Saudi Arabia, more efforts should be made to protect the youth population in areas where youth reside such as universities.

\section{Acknowledgements}

Funding: None.

Competing interests: None declared. 


\section{References}

1. Leung $\mathrm{CM}$ et al. Fighting tobacco smoking-a difficult but not impossible battle. International Journal of Environmental Research and Public Health, 2009, 6:69-83.

2. Tobacco fact sheet. World Health Organization [online factsheet] (http://www.wpro.who.int/mediacentre/ factsheets/fs_201203_tobacco/en/index.html, accessed 12 September 2013).

3. Mackay J, Eriksen M. The tobacco atlas. Geneva: World Health Organization; 2002.

4. Munif MA. Report on tobacco control program of Ministry of Health in Saudi Arabia. Riyadh, Saudi Arabia, Ministry of Health, 2009 (http://www.tcp-sa.info/photos/files/REPORT_ ON_TCP.pdf, accessed 12 September 2013).

5. Bassiony MM. Smoking in Saudi Arabia. Saudi Medical Journal, 2009, 30:876-881.

6. Al-Bedah AM et al. The Global Youth Tobacco Survey-2007. Saudi Medical Journal, 2010, 31:1036-1043.

7. Abdalla $\mathrm{AM}$ et al. Correlates of ever-smoking habit among adolescents in Tabuk, Saudi Arabia. Eastern Mediterranean Health Journal, 2009, 15:983-992.

8. [Highlights demographic survey $1428 \mathrm{H}$ (2007)]. Demographic research bulletin 1428. Saudi Arabia Central Department of Statistics and Information [online] (http://www.cdsi.gov. sa/english/index.php?option=com_docman\&task=cat_ view\&gid=43\&Itemid=113, accessed 12 September 2013) [in Arabic].

9. Jarallah JS et al. Prevalence and determinants of smoking in three regions of Saudi Arabia. Tobacco Control, 1999, 8:53-56.

10. Murthy P, Subodh BN. Current developments in behavioral interventions for tobacco cessation. Current Opinion in Psychiatry, 2010, 23:151-156.

11. Weekley CK, Klesges RC, Reylea G. Smoking as a weightcontrol strategy and its relationship to smoking status. Addictive Behaviors, 1992, 17:259-271.

12. Khader YS, Alsadi AA. Smoking habits among university students in Jordan: prevalence and associated factors. Eastern Mediterranean Health Journal, 2008, 14:897-904.
13. Dusenbury L et al. Predictors of smoking prevalence among New York Latino youth. American Journal of Public Health, 1992, 82:55-58.

14. Christophi CA et al. Main determinants of cigarette smoking in youth based on the 2006 Cyprus GYTS. Preventive Medicine, 2009, 48:232-236.

15. Johnson $\mathrm{CC}$ et al. Fifth through eighth grade longitudinal predictors of tobacco use among a racially diverse cohort: CATCH. Journal of School Health, 2002, 72:58-64.

16. Breslau N, Fenn N, Peterson EL. Early smoking initiation and nicotine dependence in a cohort of young adults. Drug and Alcohol Dependence, 1993, 33:129-137.

17. Wu IH et al. Cigarette smoking among Taiwanese adults. Epidemiology, 2011, 1:107. doi:10.4172/2161-1165.1000107.

18. Brislin RW. Back-translation for cross-cultural research. Journal of Cross-Cultural Psychology, 1970, 1:185-216.

19. Al-Damegh SA et al. Cigarette smoking behavior among male secondary school students in the Central region of Saudi Arabia. Saudi Medical Journal, 2004, 25:215-219.

20. Al-Mohamed HI, Amin TT. Pattern and prevalence of smoking among students at King Faisal University, Al Hassa, Saudi Arabia. Eastern Mediterranean Health Journal, 2010, 16:56-64.

21. Saeed AA, Al-Johali EA, Al-Shahry AH. Smoking habits of students in secondary health institutes in Riyadh City, Saudi Arabia. Journal of the Royal Society of Health, 1993, 113:132-135.

22. Al-Faris EA. Smoking habits of secondary school boys in rural Riyadh. Public Health, 1995, 109:47-55.

23. Saeed AA, Khoja TA, Khan SB. Smoking behaviour and attitudes among adult Saudi nationals in Riyadh city, Saudi Arabia. Tobacco Control, 1996, 5:215-219.

24. Al Ghobain MO et al. Prevalence and characteristics of cigarette smoking among 16 to 18 years old boys and girls in Saudi Arabia. Annals of Thoracic Medicine, 2011, 6:137-140. 